\title{
Synthesis of a Schiff Base for Carbon Sphere Modification and $\mathrm{Cd}^{2+}$ Electrochemical Determination
}

\author{
Na Li ${ }^{*}$ Xin Zhang and Hui Guo \\ Shaanxi University of Chinese Medicine, the new district of Xian-Xianyang, Shaanxi, 712046, \\ P.R.China \\ *E-mail: linaxinxin2007@163.com
}

doi: $10.20964 / 2017.12 .75$

Received: 20 August 2017 / Accepted: 10 October 2017 / Published: 12 November 2017

\begin{abstract}
In this work, a novel carbon paste electrode was chemically modified by 2-(2-hydroxyphenyl)-2,5diaza-4,6-dimethyl-8-hydroxy-1,5,7-nonatriene (SB)-coated carbon spheres, which showed excellent performance in the detection of cadmium via square-wave anodic stripping voltammetry (SWASV) with exceptional speed, simplicity, accuracy, selectivity, and sensitivity. Cyclic voltammetry (CV) and electrochemical impedance spectroscopy (EIS) measurements were then carried out for the characterization of this modified electrode. Our proposed electrode was successfully used for the detection of $\mathrm{Cd}(\mathrm{II})$ in human plasma specimens. For $\mathrm{Cd}(\mathrm{II})$, the limit of detection (LOD) was calculated as $4.6 \mathrm{pM}$ (based on a signal to noise ratio of 3), and the linearity range was found to be 10 $250 \mathrm{pM}$.
\end{abstract}

Keywords: Schiff bases; Electrochemical determination; Cd ions; Human serum; Carbon sphere

\section{FULL TEXT}

(C) 2017 The Authors. Published by ESG (www.electrochemsci.org). This article is an open access article distributed under the terms and conditions of the Creative Commons Attribution license (http://creativecommons.org/licenses/by/4.0/). 